\title{
Demographic and Clinical Study on Patients Referred to the National Cancer Research Center in Baghdad for Pap Smears
}

DOI: https://doi.org/10.32007/med.1936/jfacmedbagdad.v60i4.6

\author{
Nada A.S. Alwan* \\ Huda H.K.Al-abbody* \\ Safana A.S. Yaseen*
}

\author{
MD, PhD \\ BVMS, MSc \\ BVMS, MSc
}

(c) (9) (9)

This work is licensed under a Creative Commons Attribution-NonCommercial 4.0 International License.

\section{Abstract:}

JFac Med Baghdad 2018; Vol.60, No.4 Received Jan. 2019 Accepted April, 2019 Published: May, 2019

Background: Cervical cancer ranks the fourth most common cancer among women worldwide and the eighth cancer overall. It is considered as one of the most preventable malignancies, and can be controlled through screening and Pap smears.

Objectives: To explore the demographic and clinical characteristics of a sample of Iraqi patients who were referred to the National Cancer Research Center of the University of Baghdad for Pap smear test. Patients and methods: The study enrolled 175 female participants who were subjected to clinical examination and Pap smear tests. A questionnaire was filled for each patient on which demographic and clinical variables were recorded. Cellular specimens were collected, fixed, stained by Papanicolaou stain and examined cytologically. The corresponding cytological findings were correlated with the studied variables and tabulated accordingly.

Results: $60 \%$ of the 175 women were housewives, $40 \%$ got married before the age of 20 years, $35.4 \%$ had used contraceptive pills and $10.3 \%$ were nulliparous. The mean ages at marriage, pregnancy and first child birth were 20.2, 22.0 and 23.0 years respectively. On clinical examination, cervical erosions were obviously apparent in $41.7 \%$ of the cases and genital warts were noted in only one case $(0.6 \%)$, while koilocytotic cellular atypia was observed in 4.0\%. Pap smears revealed infections with Moniliasis and Trichomonas Vaginalis in $16.5 \%$ and $1.1 \%$ respectively. Atypical metaplastic changes, AGUS (atypical glandular cells of uncertain significance) and ASCUS (atypical squamous cells of undetermined significance) were displayed in $21.1 \%, 5.7 \%$ and $22.3 \%$ respectively. Diagnoses of CIN I (LSIL) (cervical squamous intraepithelial neoplasia 1 - low-grade squamous intraepithelial lesion), CIN II and CIN III (HSIL) (high-grade squamous intraepithelial lesion) were reported in $26.8 \%$ and $2.3 \%$ respectively. Among patients with cervical erosions, the Pap smear findings illustrated more pronounced cellular changes consistent with atypical squamous metaplasia, AGUS and ASCUS (43.8\%, $19.2 \%$ and $45.2 \%$ respectively). On the other hand, LSIL, kiolocytotic atypia and HSIL in these cases were registered in $15.1 \%, 6.8 \%$ and $1.3 \%$ respectively.

Conclusions: The demonstrated young ages at marriage, pregnancy and childbirth of the examined patients, reflecting the early onset of sexual reproductive activities, and the associated cellular changes urge the necessity for promoting public awareness on the significance of Pap smear screening among Iraqi females. The Bethesda system facilitates easier interpretation of the results; thus fostering the communications between the examining pathologists and the gynecologists.

Key words: Demograph , clinic, Pap, smears, women.

\section{Introduction:}

Globocan estimates worldwide for 36 cancers in 185 countries shows that cervical cancer ranks as the fourth most common cancer among women and the eighth cancer overall. There were over 500,000 new cases in 2018 (1). This malignancy usually develops slowly and has readily detectable lesions that can be easily managed through early diagnosis and

*The Iraqi National Cancer Research Center, University of Baghdad,

Correspondence Email: nadaalwan@yahoo.com

hudaalabbody@gmail.com

safanaaltaem@yahoo.com treatment (2). The most significant risk factor for becoming susceptible to develop cervical cancer is infection by the carcinogenic types of Human Papilloma Virus (HPV), namely 16 and 18. Nevertheless, other established causes include promiscuous life style associated with exposure to early sexual experience, high number of sexual partners, smoking and low socio-economic status (3).

Although the prevalence rates of cervical cancer recorded by the Iraqi Cancer Registry is low, similar to other Islamic countries, many of the registered cases often present in advanced stages thus hindering the chances for cure $(1,4-8)$. Previous 
studies from Iraq have directed the attention to the importance of promoting Pap smears to diagnose cervical intraepithelial neoplastic (CIN) lesions among Iraqi females focusing on the significance of increasing awareness on the preventive measures to control that disease (5-8). Incorrect knowledge, attitudes and practices related to breast cancer (910), cervical cancer and Pap smears (8) were reported among educated Iraqi females.

In general, awareness on the prevention and treatment strategies for cervical cancer are suboptimal in developing countries where the disease is most prevalent (1,3). Cervical cancer control programs have been developed by the WHO for implementation in low-resource settings provisionally based on promoting public education on screening using Pap smear test, HPV detection and visual inspection of the cervix $(3,11,12)$. In more developed countries, colposcopy, cervical cytology and HPV detection remain the main screening tools for detecting cervical cancer $(2,3,8$ 13).

This study was conducted to explore the demographic and clinical characteristics of a sample of Iraqi patients who were referred to the National Cancer Research Center of the University of Baghdad for Pap smear tests.

\section{Cases and Methods:}

Patients: A total of 175 female patients 16-67 years of age (mean $39 \pm 10$ ) referred by senior gynecologists to the National Cancer Research Center (NCRC) of the University of Baghdad during (January of 2014- December of 2017) for checkingup and inspection. All the referred patients were fully aware about the Pap smear test before the procedure was undertaken. A questionnaire was filled for each patient where demographic and clinical variables were recorded including age, marital, menstrual and menopausal status, and parity, history of contraception or hormone replacement therapy. The cervical appearance was assessed clinically and were correlated with the cytological findings.

\section{Cervical Examination and Pap Smears}

After thorough history, each patient was subjected to clinical and gynecological examinations at the Colposcopy Clinic of the Clinical Examination Department belonging to the NCRC. The patients were placed in lithotomy position where visual inspection of the cervix was carried out to record the cervical and vaginal appearances. Then, the Pap smears were collected from the participants using Ayre's spatula and a broom brush after appropriate explanation of the procedure to the woman (14). The spatula and the pointed tip of the brush were introduced through the external cervical os where the squamo-columnar junction was scraped by rotating 360 degrees to include cells from the internal os. Then the specimens were directly smeared in an even manner onto prepared frosted slides on which the patient's name and serial number were recorded. Slides were immediately fixed in $99 \%$ ethanol or absolute alcohol for at least 20 minutes.

The fixed smears were stained according to Papanicolaou. Slides were dipped in descending concentrations of ethanol $(95 \%, 80 \%, 70 \%$ and $50 \%$ ) each for 10 dips, and then dipped for 10 times in distilled water. That was followed by immersing for 1-2 min in a jar containing Hematoxylin stain. Excessive stain was removed by subjecting the slides to running tap water, followed by ascending concentrations of ethanol $(50 \%, 70 \%, 80 \%$ and 95\%) dipping slides for 10 times in each concentration. Subsequently, the slides were placed in Orange-G stain for $2 \mathrm{~min}$, followed by 10 dips in 95\% ethanol and then Eosin stain for another 2 minutes. That was followed by immersing the slides in $95 \%$ ethanol twice, absolute ethanol and a mixture of 50:50 absolute ethanol and Xylene for 5 minutes. Finally, the slides were left in Xylene for at least 30 minutes to be mounted with Canada Balsam or DPX (mixture of distyrene, a plasticizer, dissolved in Xylene).

All the slides were examined by senior pathologists under the light microscope using different magnifications within the Department of Pathology Research of the NCRC. Pap smears were classified according to the CIN (Cervical Intra-epithelial Neoplasia) terminology and the Bethesda system. The corresponding examined cytological findings were linked with the studied demographic and clinical variables.

\section{Statistics}

The data was analyzed by using computer software Statistical Package for Social Sciences (SPSS Inc,.Chicago, IL, USA) version16. Data was represented as frequencies, percentages, means and standard deviations (SD) of the variables. The results were tabulated according to the observed clinical and cytological findings.

\section{Results:}

Table (1) shows the main demographic and clinical features of the cases included in the study. The peak age frequency was in the fifth decade of life; $60 \%$ were housewives and $37.1 \%$ were employed. The majority $(96 \%)$ said that they were married at the time of the study; $30.3 \%$ have never used any contraception while $35.4 \%$ have used contraceptive pills. More than $40 \%$ got married before the age of 20 years and only $1.7 \%$ got married at the age of 40 years or over. The menstrual period was regular in $64.6 \% ; 10.3 \%$ were nulliparous while approximately $60 \%$ had more than two children. The main reasons for referral were abnormal vaginal discharge $(35.4 \%)$, routine check-up $(23.4 \%)$ and post-coital bleeding $(22.3 \%)$. History of performing previous Pap smears was reported by $35.4 \%$ of the referred patients. 
Table (1): Demographical and Clinical Characteristics of the Study Sample

\begin{tabular}{|c|c|c|c|c|c|}
\hline $\begin{array}{l}\text { Characteristics of the Study } \\
\text { Sample }\end{array}$ & No of Cases & $\%$ & Characteristics of the Study Sample & No of Cases & $\%$ \\
\hline Current Age (years) & & & Age at Marriage (years) & & \\
\hline$<20$ & 3 & 1.7 & $<20$ & 71 & 40.6 \\
\hline $20-29$ & 38 & 21.7 & $20-29$ & 82 & 46.9 \\
\hline $30-39$ & 47 & 26.9 & $30-39$ & 19 & 10.9 \\
\hline $40-49$ & 64 & 36.6 & 40 or $>$ & 3 & 1.7 \\
\hline$>50$ & 23 & 13.1 & & & \\
\hline Occupation & & & Marital Status & & \\
\hline House Wife & 105 & 60.0 & Married & 168 & 96 \\
\hline Employed & 65 & 37.1 & Widowed & 5 & 3.4 \\
\hline Retired & 1 & 1.7 & Divorced & 2 & 0.6 \\
\hline Student & 2 & 1.1 & & & \\
\hline Contraception & & & Menstrual Period & & \\
\hline No Use & 53 & 30.3 & Regular & 113 & 64.6 \\
\hline Pill & 62 & 35.4 & Irregular & 62 & 35.4 \\
\hline Condom & 23 & 13.1 & & & \\
\hline Coitus Interruptus & 6 & 3.4 & & & \\
\hline IUD & 26 & 14.9 & & & \\
\hline the purpose from the visit & & & Parity & & \\
\hline Routine Check-up & 41 & 23.4 & Nil & 18 & 10.3 \\
\hline Post-coital bleeding & 39 & 22.3 & $1-2$ & 53 & 30.3 \\
\hline Dyspareunia & 21 & 12 & $3-5$ & 81 & 46.3 \\
\hline Irregular vaginal bleeding & 12 & 6.9 & $6+$ & 23 & 13.1 \\
\hline Abnormal vaginal discharge & 62 & 35.4 & & & \\
\hline \multicolumn{6}{|l|}{ History of Pap Smear } \\
\hline Yes & 62 & 35.4 & & & \\
\hline No & 113 & 64.6 & & & \\
\hline Total & 175 & 100 & Total & 175 & 100 \\
\hline
\end{tabular}

The age of the patients in this study ranged between 17-67 years with a mean of $38.8 \pm 10.68$ (Table 2). The mean ages at first marriage, first pregnancy and first child birth were 20.2, 22.0 and 23.0 years respectively. The youngest reported ages at first marriage, first pregnancy and first child birth were 12,14 and 15 years respectively. The ages of the patients who have reached menopause ranged between 38-55 years with a mean of 48.7 .

Table (2): Correlation of Age with the Reproductive Status.

\begin{tabular}{|c|c|c|c|c|}
\hline Variable & $\begin{array}{l}\text { No. of } \\
\text { Cases }\end{array}$ & Range & Mean & $\begin{array}{l}\text { Standard } \\
\text { Deviation }\end{array}$ \\
\hline Age (years) & 175 & $17-67$ & 38.8 & 10.68 \\
\hline $\begin{array}{l}\text { Age at } \\
\text { Marriage }\end{array}$ & 175 & $12-45$ & 20.2 & 6.36 \\
\hline $\begin{array}{l}\text { Age at } \\
\text { Pregnancy }\end{array}$ & 157 & $14-42$ & 22.0 & 8.43 \\
\hline $\begin{array}{l}\text { Age at First } \\
\text { Child Birth }\end{array}$ & 157 & $15-43$ & 23.0 & 8.46 \\
\hline $\begin{array}{ll}\text { Age } & \text { at } \\
\text { Menopause }\end{array}$ & 22 & $38-55$ & 48.7 & 4.45 \\
\hline
\end{tabular}

On visual inspection of the uterine cervix of the examined patients, Table (3) illustrates that in $40.5 \%$ the cervix looked normal while erosion was obviously apparent in $41.7 \%$ of the cases. Genital warts were noticed in only one case $(0.6 \%)$. Papanicolaou stained smears revealed non-specific inflammatory cellular changes in $82.3 \%$; Candida albicans (Moniliasis) and Trichomonas Vaginalis were reported in $16.6 \%$ and $1.1 \%$ of the cytologically examined cases respectively. Atypical changes within the metaplastic cells were displayed in $21.1 \%$, AGUS (Atypical Glandular Cells of Undetermined Significance in 5.7\% and ASCUS (Atypical Squamous Cells of Undetermined Significance in 22.3\%. CIN I (Cervical Intraepithelial Neoplasia type I) classified by the Bethesda system as LSIL (Low-Grade squamous Intraepithelial Lesion), CIN II and CIN III classified by the Bethesda system as HSIL (High-Grade squamous Intraepithelial Lesions) were diagnosed in $26.9 \%$ and $2.3 \%$ respectively. Koilocytotic cellular atypia suggesting HPV infection (classified within LSIL) was noted in seven cases (4.0\%).

\section{Table (3): Clinical and Cytopathological Findings on Cervical Examination.}

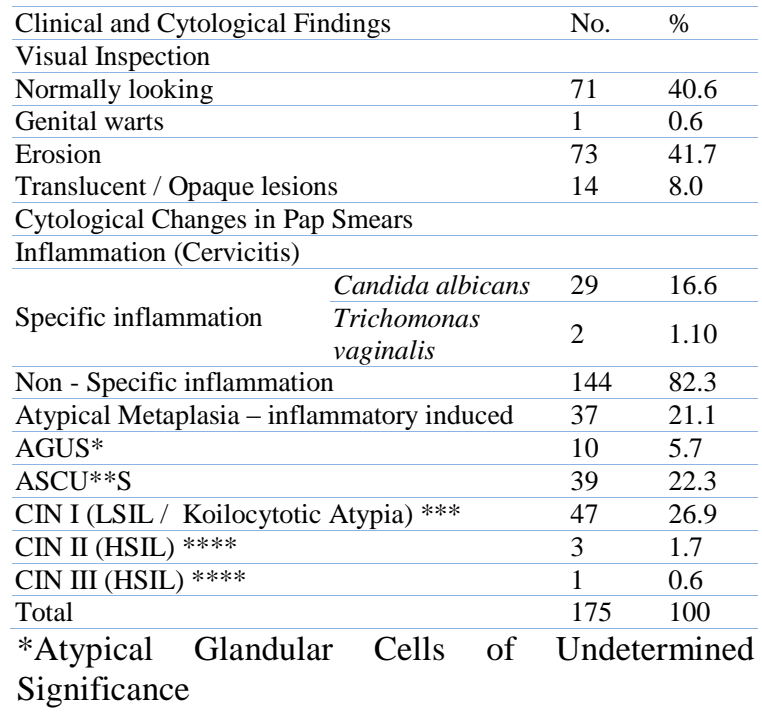




\author{
**Atypical Squamous Cells of Undetermined \\ Significance \\ ***Cervical Intraepithelial Neoplasia (Low-Grade \\ squamous Intraepithelial Lesion) \\ **** High-Grade squamous Intraepithelial Lesion
}

Among the 73 patients who had cervical erosions, the Pap smear findings revealed specific cervicitis due to Moniliasis and Trichomonas Vaginalis in $13.7 \%$ and $1.4 \%$ respectively. More pronounced cellular changes consistent with atypical squamous metaplasia, AGUS and ASCUS were observed in $43.8 \%, 19.2 \%$ and $45.2 \%$ respectively. On the other hand, the rates of CINI (LSIL) and CIN II (HSIL) did not exceed $15 \%$ and $1.4 \%$ respectively. While no case showed cellular changes consistent with CIN III,

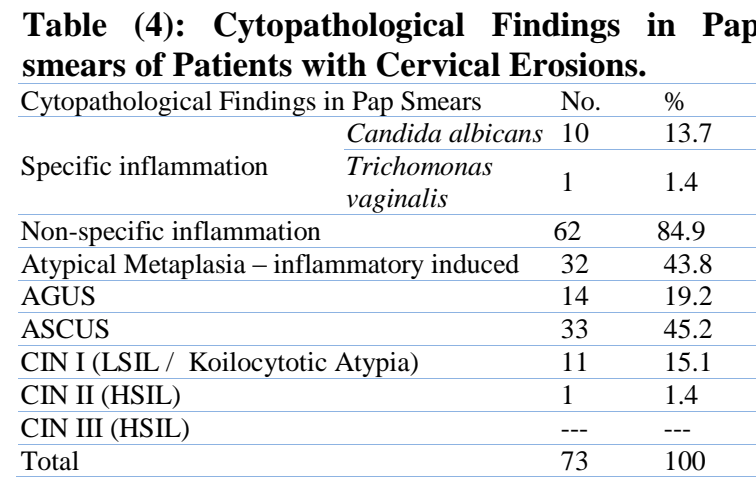

\section{Discussion:}

In developing countries, where awareness and facilities for the prevention and treatment of the diseases are obviously inadequate, cervical cancer ranks as one of the most common cancers among women and the leading cause of cancer related mortality $(1,3)$. The World Health Organization has developed guidelines for cervical cancer control strategies in low-and middle resource settings focusing upon promoting public health education and screening for that type of malignancy through Pap smears, detection of HPV and visual inspection of the cervix (3, 10-14). The National Cancer Research Center of the University of Baghdad was established to emphasize the role of research in adopting the national cancer control strategy, to raise the awareness of the Iraqi population to the signs and symptoms of common cancers through public education and to build capacities of the health professionals through training in the fields of cancer diagnosis and treatment $(15,16)$. This study documented the demographic and clinical characteristics of the patients who were referred to the center for checking up and consultation. The early age at first marriage, pregnancy and birth in the study group points out to the critical role of early sexual activity on exposure of the reproductive system to infectious agents and carcinogens including HPV $(17,18)$. Over $35 \%$ of the cases had positive history of using oral contraceptive pills. Although earlier studies showed that there might be a significant correlation between abnormal Pap smear findings and hormonal contraception (19), yet a more recent Australian cross-sectional study documented that the duration of oral contraceptive use among women with Pap smear changes consistent with CIN was significantly shorter than those without abnormalities; indicating that oral contraceptives could be inversely associated with CIN (20). The value of Pap smears in detecting cellular abnormalities has been well documented in the literature as the most successful screening tool for cervical cancer; specifically when applied together with Colposcopy and HPV tests (3, 11-14). Studies from Iraq found that the high agreement rate between cervical cytology and colposcopy indicates that conventional Pap smear could be considered as a dependable screening test in spite of its relatively low sensitivity $(8,22)$. Nevertheless, better results could be achieved through the liquid-based cytology procedure in which a suspension from the sample is used to produce a thin layer of cells on a slide; thus allowing clearer vision and accurate diagnosis. That technique could be maneuvered manually in scarce resource settings (23). Pap smear examination of the specimens in the current study showed that in $16.5 \%$ of the cases there was evidence of fungal spores indicating Moniliasis while moderate-severe cervicitis extending to the endocervix was observed in $39 \%$. Thus it was not surprising that the main reasons for referral were abnormal vaginal discharge (35.4\%) and post-coital bleeding (22.3\%). In a previous Iraqi study it was reported that vaginal secretions, abdominal pain and itching were the most important signs of cervical inflammation (22). Severe cervicovaginitis could obscure serious CIN lesions resulting in false negative findings (14). Although it is claimed that such dilemma could be reduced by applying liquid based cytology, yet some studies failed to reveal a significant difference in the overall accuracy of conventional Pap test versus liquid based cytology (24). Overall, atypical cellular changes in the form of atypical squamous metaplasia, AGUS and ASCUS were diagnosed in $21.1 \%, 5.7 \%$ and $22.3 \%$ while CIN I (LSIL), CIN II and CIN III (HSIL) were diagnosed in $26.8 \%$ and $2.3 \%$ respectively. Koilocytotic cellular atypia suggesting HPV infection (classified within LSIL) was noted in seven cases $(4.0 \%)$. The NCRC reports cervical cytology diagnoses in Pap smears using the Bethesda system as well which was introduced in 1988 and revised in 2001 (25). The terminology reflects the biological concepts underlying precancerous lesions that were earlier referred to as cervical dysplasia (mild, moderate or severe) or cervical intra-epithelial neoplasia (CIN 1, CIN II or CIN III). It comprises low grade squamous intraepithelial lesion (LSIL) which include koilocytotic atypia and high grade squamous intraepithelial lesion (HSIL). A previous study on symptomatic Iraqi patients referred to the Cytopathology Teaching Laboratory of the Medical City Teaching Hospital demonstrated rates for 
ASCUS, AGUS, LSIL and HSIL equivalent to $36.1 \%, 7.2 \%, 33.7 \%$ and $3.6 \%$ respectively (26). The relatively high rates of abnormal Pap smears in this study is attributable to the fact that approximately $77 \%$ of the patients were referred to the center complaining of serious signs and symptoms. On visual inspection of the uterine cervix of the examined patients, $40.5 \%$ had normal appearance while erosion was obviously apparent in $41.7 \%$ of the cases (73 cases). Genital warts were obviously visualized as palpable lesions in only one patient who had Pap smear findings consistent with koilocytotic atypia. Pap smear cytological specimens from the erosive cervices showed relatively higher rates of mild atypical cellular changes; yet they were not associated by more serious intraepithelial neoplastic cellular changes. Koilocytotic atypia suggestive of HPV infection was displayed cytologically in $6.8 \%$ of the patients who were complaining of cervical erosions in this study. In general, it has been reported that cytological or histological signs of HPV infection cannot be detected in a majority of women who are positive for HPV (27); since the presence of koilocytes may be difficult to diagnose specifically when there are slide fixation or dehydration artifacts resulting in cells exhibiting peri-nuclear halos (28).

\section{Conclusions}

The demonstrated young ages at marriage, pregnancy and childbirth of the examined patients, reflecting the early onset of sexual reproductive activities, and the associated cellular changes urge the necessity for promoting public awareness on the significance of screening among the Iraqi female community. Pap smear remains a safe, acceptable, cost effective and reproducible technique for early detection of cervical cell abnormalities. The Bethesda system facilitates easier interpretation of the results; thus fostering the communications between the examining pathologists and the gynecologists and allowing clear guidance for clinical management.

\section{Authors' contributions:}

This study was designed and drafting the manuscript was done by Nada A. Alwan. The study was conceived, input and output the data in the statistical program by Huda H. Alabbody. The results were analyzed by Nada A. Alwan, Huda H. Alabbody and Safana A. Yaseen ${ }^{3}$

\section{References:}

1. Bray F, Ferlay J, Soerjomataram I, Siegel RL, Torre LA, Jemal A. Global Cancer Statistics 2018: GLOBOCAN estimates of incidence and mortality worldwide for 36 cancers in 185 countries. CA Cancer J Clin, in press. The online GLOBOCAN 2018 database is accessible at http://gco.iarc.fr/, as part of IARC's Global Cancer Observatory.

2. Arbyn $M$, Ronco $G$, Anttila A, Meijer CJ, Poljak M, Ogilvie $G$, et al: Evidence regarding human papillomavirus testing in secondary prevention of cervical cancer. Vaccine. 2012;. 30 Suppl 5: F88-F99.

3. Comprehensive cervical cancer control: a guide to essential practice - 2nd ed. WHO Library Cataloguing-in-Publication Data. World Health Organization, 2014.

4. Iraqi Cancer Board. Results of the Iraqi Cancer Registry 2012. Baghdad, Iraqi Cancer Registry Center, Ministry of Health, 2015.

5. Al-Alwan N: The Fate of Mild Cervical Dysplasia: a long-term cytologic follow-up study of 252 patients. J. Fac. Med. Baghdad Univ. 1995; 37: 237-244

6. Al Shimmary I and Al-Alwan N: Significance of Cervical Cytology (Pap smears) in the Detection of Precancerous Cervical Lesions. J. Fac. Med. Baghdad Univ. 2007; 49 (3): 315-322.

7. Alwan NAS, Al-Attar WM, Al Mallah N, Abdulla K. Assessing the Knowledge, Attitude and Practices towards Cervical Cancer Screening among a sample of Iraqi Female Population, Iraqi Journal of Biotechnology, 2017; 16 (2): 37-47.

8. Al-Alwan N: Colposcopy, Cervical Cytology and Human Papillomavirus Detection as Screening tools for Cervical Cancer. Eastern Mediterranean Health Journal, WHO, EMRO, 2001; 7 (1/2): 100105.

9. Alwan N, Al-Attar W, Eliessa R, Al-Midfaei Z \& Nidhal F: Knowledge, Attitude and Practice regarding Breast Cancer and Breast SelfExamination among a Sample of the Educated Population in Iraq. Eastern Mediterranean Health Journal, WHO, EMRO, 2012; 18 (4): 337-345.

10. Alwan NAS and Al-Attar: Evaluating the Effect of an Educational Teaching Model on the Knowledge about Breast Cancer among Female University Students in Iraq., JJ Cancer Sci. Res. 2016, 2(1): 026,

11. Cervical cancer screening in developing countries: Report of a WHO consultation. WHO Library Cataloguing-in-Publication Data. World Health Organization, 2002.

12.WHO Cancer control. Knowledge into Action. WHO Guidelines for Effective Programmers. Early Detection. WHO Publ. Geneva, Switzerland, 2007.

13. Hakan D, Ersin N; Muhsin A: Cervical Cancer Screening in Turkey: A Community-based Experience After 60 Years of Pap Smear Usage. 9Asian Pacific Journal of Cancer Prevention, 2012; 13 (12): 6497-6500

14. Bibbo $M$ and Wilbur D: Comprehensive Cytopathology: Elsevier, 2014.

15. Alwan N, Kerr D. Cancer Control in War-Torn Iraq, The Lancet Oncology, 2018; 19 (3): 291-292 16. Al Alwan N: Establishing Guidelines for Early Detection of Breast Cancer in Iraq. Int. J. of Advanced Research. 2015; 3 (12): 539-555

17. Dudgeon MR, Inhorn MC. Men's influences on women productive health: medical anthropological perspectives. Social Science \& Medicine. 2004; 59:1379-1395. 
18. Sankaranarayanan $R$, Nene BM, Shastri SS, Jayant $K$, et al: HPV screening for cervical cancer in rural India. $N$ Engl J Med, 2009; 60 (14):13851394.

19. Gorenoi, Vitali, Matthias P. Sch $\square$ nermark, and Anja Hagen. "Benefits and risks of hormonal contraception for women." GMS Health Technology Assessment, 2007; Vol. 3.

20. Chih HJ, Lee AH, Colville L, Xu D, Binns CW. Condom and oral contraceptive use and risk of cervical intraepithelial neoplasia in Australian women. J Gynecol Oncol, 2014; 25 (3): 183-187.

21. Barzangi BK. Assessment of the validity of pap smear cytology in diagnosing cervical intraepithelial neoplasia in the maternity teaching hospital in Erbil city. Zanco J. Med. Sci., 2011; 15 (3): 64-69.

22. Abdulla KN, Alheshimi SJ, Skheel Aljebory HD, Altaei TJ. Evaluation of Pap smear data in Baghdad province. International J Sci and Res Pub. 2016; 6 (5): 634-639

23. Nandini NM, Nandish SM, Pallavi P, Akshatha SK, Chandrashekhar AP, Anjali S, et al. Manual liquid based cytology in primary screening for cervical cancer-a cost effective preposition for scarce resource settings. Asian Pac J Cancer Prev. 2012;13:3645-51.
24. ACOG Committee on Practice Bulletins-Gynecology. ACOG Practice Bulletin no. 109: Cervical cytology screening .Obstet Gynecol 2009;114:1409-20

25. Nayar R, Wilbur D. The Bethesda S ystem for Reporting Cervical Cytology, Definitions, Criteria, and Explanatory Notes. Springer; 2015

26.Al-Rubaiee $N \&$ Al-Alwan N: "Application of the Behesda System for Cervical Cytology Reporting". J Fac Med Baghdad. J, , Baghdad Univ. 2006; 48 (1): 41-47.

27. Stefan Miladinov Kovachev \& Victor Dimitrov Slavov Correlation between abnormal cytological findings and human papillomavirus infection of the uterine cervix in Bulgarian women, Biotechnology \& Biotechnological Equipment, 2016; 30:6, 11681172.

28.IARC Working Group on the Evaluation of Carcinogenic Risk to Humans. Human papillomaviruses. Vol. 90, IARC monographs on the evaluation of carcinogenic risks to humans. Lyon: International Agency for Research on Cancer; 2007. Chapter 1, HPV infection. Available from: http://www.ncbi.nlm.nih.gov/books/NBK321770/ 
دراسة ديموغر افية وسريرية للمريضات المحالات إلى المركز الوطني لبحوث السرطان في بغداد لأجراء مسحات عنق

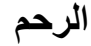

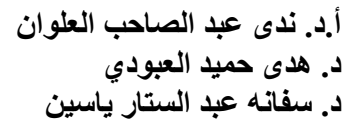

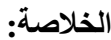

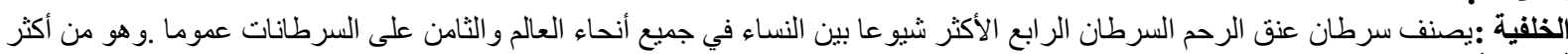

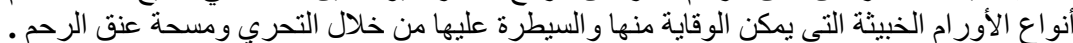

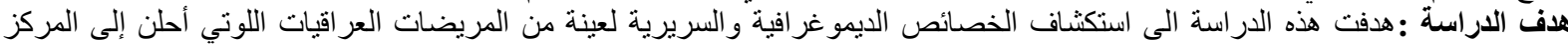

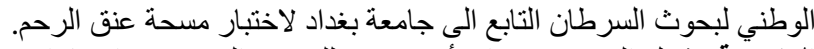

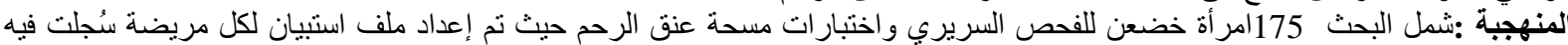

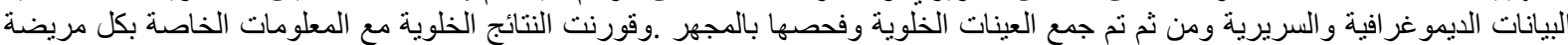

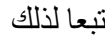

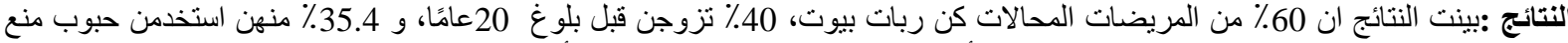

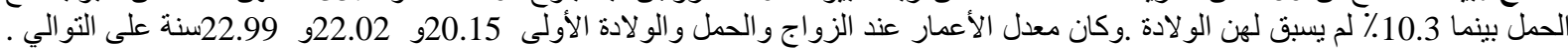

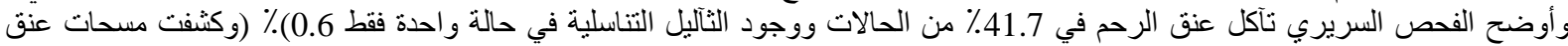

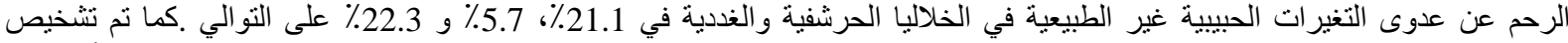

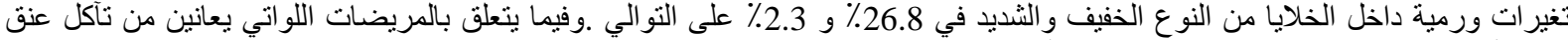

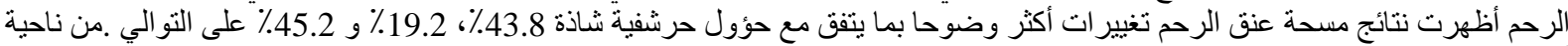

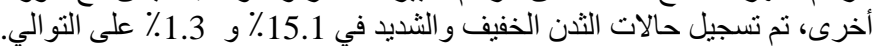

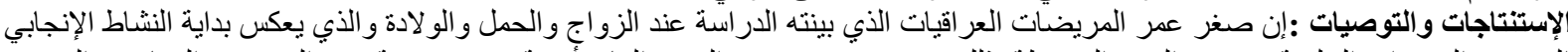

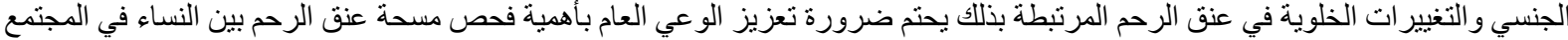

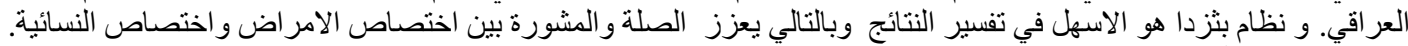

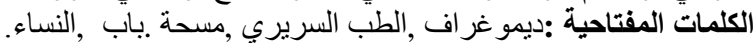

